\title{
Clinical heterogeneity and novel mutations in the glycerol kinase gene in three families with isolated glycerol kinase deficiency
}

\author{
D R Sjarif, R J Sinke, M Duran, F A Beemer, W J Kleijer, J K Ploos van Amstel, \\ B T Poll-The
}

University Children's Hospital "Het Wilhelmina Kinderziekenhuis", Nieuwegracht 137, 3512 LK Utrecht, The Netherlands D R Sjarif M Duran

B T Poll-The

Clinical Genetics

Center Utrecht, PO

Box 18009, 3501 CA

Utrecht, The

Netherlands

R J Sinke

F A Beemer

J K Ploos van Amstel

Department of Clinical

Genetics, University

Hospital, Erasmus

University, Rotterdam,

The Netherlands

W J Kleijer

Correspondence to:

Professor Poll-The.

Received 9 September 1997 Revised version accepted for publication 26 January 1998

\begin{abstract}
Isolated glycerol kinase deficiency (GKD) is an $X$ linked recessive disorder. The clinical and biochemical picture may vary from a childhood metabolic crisis to asymptomatic adult "pseudohypertriglyceridaemia", the result of hyperglycerolaemia. We performed glycerol kinase (GK) gene analysis to study the molecular heterogeneity and genotype-phenotype correlation in eight males from three families with isolated GKD. All patients had hyperglycerolaemia and glyceroluria. Four patients from two families were essentially free of symptoms. Three patients had gastrointestinal symptoms with ketoacidosis or hypoglycaemia or both. One patient had recurrent convulsions as the only acute sign, without evidence that it was correlated with a catabolic state. Fasting tests in two symptomatic patients of family 1 showed hyperketotic states, together with a tendency to hypoglycaemia. The diagnosis was confirmed by a defective ${ }^{14} \mathrm{C}$-glycerol incorporation into trichloroacetic acid precipitable macromolecules in intact skin fibroblasts. Mutation screening of the GK gene was performed by amplification and direct sequencing of exons using PCR. Three novel mutations were identified: (1) a deletion starting downstream of exon 9 , extending to the 3 ' end of the gene; (2) a nonsense mutation $R 413 X$ caused by a C1351T transition; and (3) a missense mutation W503R caused by a T1651C transition. In addition, we found differences from the reported sequence: (1) exon 9 actually consists of two exons, which consequently will change the number of GK gene exons from 19 to 20 exons, and (2) nucleotide differences in exon 19. So far, no genotype-phenotype correlation can be established in these GKD families.

$(\mathcal{M}$ Med Genet 1998;35:650-656)
\end{abstract}

Keywords: isolated glycerol kinase deficiency; novel mutation; gene structure; hyperketotic hypoglycaemia

Glycerol kinase deficiency (GKD, MIM 307030) is an $X$ linked recessive disorder characterised biochemically by hyperglycerolaemia and glyceroluria. Three distinct clinical phenotypes of this enzymopathy exist, the complex infantile, juvenile, and benign or adult forms.
The complex infantile form is an $\mathrm{Xp} 21$ contiguous gene syndrome involving the glycerol kinase (GK) locus together with the congenital adrenal hypoplasia or Duchenne muscular dystrophy loci or both. ${ }^{1}$ The clinical features of a patient with complex GKD depend on the loci that are involved, and may be associated with mental retardation and dysmorphic features. ${ }^{23}$ The juvenile and adult forms are the result of an isolated GK deficiency. Affected boys with the juvenile form may present in childhood with episodes of a Reye-like syndrome, including vomiting, metabolic acidosis, ketotic hypoglycaemia, and progressive lethargy or unconciousness during intercurrent illness. The benign or adult form of isolated GKD is not associated with clinical symptoms. Males with this phenotype are identified with an asymptomatic "pseudohypertriglyceridaemia" as a result of a raised plasma glycerol. The diagnosis of GKD can be confirmed by (1) the measurement of the enzyme activity in a variety of tissues, including leucocytes, cultured skin fibroblasts, and amniocytes, transformed lymphoblastoid cell lines, liver, kidney, and small intestine, and (2) the incorporation of ${ }^{14} \mathrm{C}$-glycerol into trichloroacetic acid precipitable macromolecules in intact skin fibroblasts. ${ }^{4}$

The human GK gene has been mapped to $\mathrm{Xp} 21.3 .^{5-7}$ The gene spans approximately 50 $\mathrm{kb}$ and comprises 19 exons. $^{7}$ The major GK mRNA has a reported length of $2581 \mathrm{bp}$ and encodes a protein with a length of 553 amino acids. ${ }^{78}$ In addition to this functional gene, several regions of sequence homology to the $\mathrm{Xp}$ gene have been identified: the pseudogenes at $1 \mathrm{q} 41$ and Xq23, the processed, expressed genes at $4 \mathrm{q} 13$ and $4 \mathrm{q} 32$, and the anonymous sequences of unknown status on chromosomes 4 and Xq. ${ }^{7}$

To date, only one missense mutation, one splice site mutation, and one small deletion have been reported for isolated GKD in four patients. ${ }^{9}$ To elucidate further the molecular heterogeneity and to study the genotypephenotype relationship in isolated GKD, clinical, biochemical, and molecular analysis of three unrelated families are presented.

\section{Patients and methods}

PATIENTS

Family 1

This white Dutch family has four males affected with isolated GKD (fig 1A). The proband (1.III.1), a 12 year old boy, was diagnosed at 20 
A Family 1
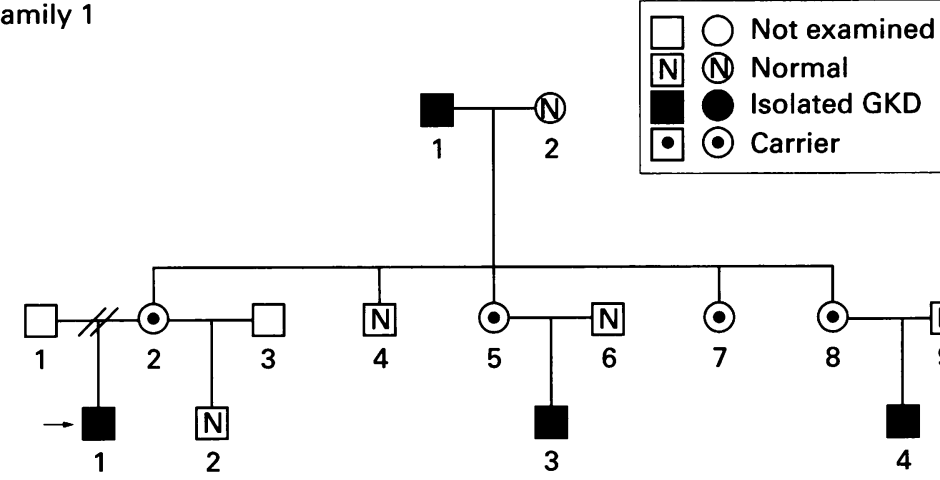

III

B Family 2

I

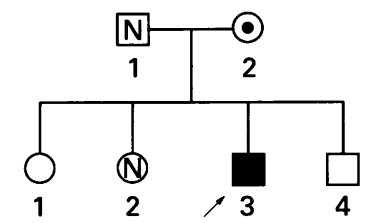

C Family 3

।

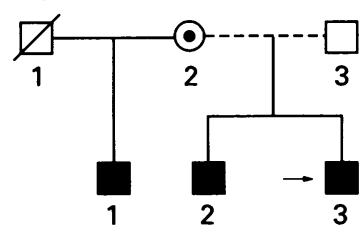

Figure 1 Pedigrees of families 1,2, and 3. The arrows indicate the probands.

months of age. In retrospect he had presented initially with metabolic acidosis in the first week of life. He was a small for gestational age infant, with a birth weight of $2075 \mathrm{~g}$. He was admitted to hospital several times with lethargy preceded by fever and vomiting/diarrhoea, interpreted as a viral infection. One of these episodes was associated with metabolic acidosis $(\mathrm{pH} 7.27$, base deficit $-10.5 \mathrm{mmol} / \mathrm{l}$ ) and ketonuria. At 7 months of age, he had a mild convergent strabismus and right inguinal hernia. Growth and mental development were normal. His half brother (1.III.2) had normal values of serum and urine glycerol. The second patient (1.III.3), an $81 / 2$ year old boy, experienced only a single episode of hypoglycaemia (glucose $0.8 \mathrm{mmol} / \mathrm{l}$ ) in the first few hours of life. He was also a small for gestational age infant, with a birth weight of $2450 \mathrm{~g}$. There were facial dysmorphism (square face, frontal bossing, and low set, mildly dysmorphic ears), a hypoplastic right thumb, and cryptorchidism. His height was on the $3 \mathrm{rd}$ centile. Cytogenetic investigation showed a normal male karyotype. GKD was diagnosed at $11 / 2$ years of age, because his mother was at risk of being a GKD carrier. A low fat and carbohydrate rich diet was prescribed after the diagnosis had been made. So far, he has experienced

no clinical hypoglycaemic episodes. The third patient (1.III.4), a 11/2 year old boy, had been evaluated in the neonatal period. His birth weight of $3450 \mathrm{~g}$ was normal. So far, he has experienced no hypoglycaemic episodes, and somatic and psychomotor development were normal. The fourth patient in this family (1.I.1) was the healthy 62 year old maternal grandfather. He has never experienced any clinical episode of hypoglycaemia. None of the patients showed any evidence of myopathy or adrenal insufficiency.

\section{Family 2}

Patient 2 (2.II.3), a white Dutch boy, presented at 3 years of age with ketoacidosis ( $\mathrm{pH} 7.23$, base deficit $-13.7 \mathrm{mmol} / \mathrm{l}$, and ketonuria) preceded by vomiting. Mild psychomotor retardation and an attention deficit disorder were noted at that time. At 8 years his growth was normal. No other family members were known to be affected (fig 1B).

\section{Family 3}

The proband (3.II.3), a 11/2 year old Indonesian boy (according to maternal ethnicity), presented at 10 months of age with generalised seizures, for which he was placed on antiepileptic drug therapy. No laboratory data of the period before the onset of seizures were available. His psychomotor development was delayed. His older (half) brothers, patients 3.II.1 and 3.II.2, aged 8 and $31 / 2$ years respectively (fig 1C), were also affected by isolated GKD. They have never experienced any clinical episode of hypoglycaemia and they developed normally.

\section{BIOCHEMICAL ANALYSIS}

The probands in each family were identified by the finding of urinary glycerol in the course of organic acid analysis as part of a selective screening programme for inborn errors of metabolism. Quantitative analysis of glycerol was determined using a standard triglyceride assay with omission of the hydrolysis step. Incorporation of ${ }^{14} \mathrm{C}$-glycerol into trichloroacetic acid precipitable macromolecules was used as an indirect measure of GK activity in situ in intact cultured skin fibroblasts. ${ }^{4}$ The clinical and biochemical data of the families are presented in table 1 . The levels of serum creatine kinase and cortisol of all patients did not

Table 1 Clinical and biochemical findings of the three families with isolated GKD

\begin{tabular}{|c|c|c|c|c|c|c|}
\hline Patient & $\begin{array}{l}\text { Age of } \\
\text { onset }\end{array}$ & First symptoms & Additional symptoms; age at last examination & $\begin{array}{l}\text { Glycerol in } \\
\text { plasma }{ }^{\star} \\
\text { (mmol/l) }\end{array}$ & $\begin{array}{l}\text { Glycerol in } \\
\text { urinet } \\
\text { (mmoll } \\
\text { mmol } \\
\text { creatine) }\end{array}$ & $\begin{array}{l}{ }^{14} C \text {-glycerol } \\
\text { incorporation } \\
\text { in skin } \\
\text { fibroblasts (\% } \\
\text { of normal) }\end{array}$ \\
\hline \multicolumn{7}{|l|}{ Family 1} \\
\hline I.1 & - & None & None; $62 \mathrm{y}$ & 5.5 & 32 & 0.1 \\
\hline III. 1 & $20 \mathrm{mth}$ & Gastrointestinal symptoms and ketoacidosis & SGA, mild convergent strabismus, inguinal hernia; $12 \mathrm{y}$ & 5.2 & 48 & 0.1 \\
\hline III. 3 & $1 \mathrm{~d}$ & Hypoglycaemia & $\begin{array}{l}\text { SGA, dysmorphic face, hypoplastic thumb, } \\
\text { cryptorchidism; } 10 \mathrm{y}\end{array}$ & 6.4 & 38 & 0.1 \\
\hline II. 3 & $3 y$ & Vomiting and ketoacidosis & Psychomotor retardation, hydrocele; 8 y & 1.3 & 47 & 0.2 \\
\hline \multicolumn{7}{|c|}{ Family 3} \\
\hline II.1 & - & None & None; 8.5 y & 5.1 & 24 & 0.3 \\
\hline II. 2 & - & None & None; 4 y & 5.4 & 41 & 0.3 \\
\hline II. 3 & $10 \mathrm{mth}$ & Generalised seizures & Axial hypotonia, psychomotor retardation; 2 y & 3.6 & 66 & 0.3 \\
\hline
\end{tabular}

*Control value: $0-0.28 \mathrm{mmol} / 1$. †Control value: undetectable. SGA: small for gestational age. 
Table 2 Primers used for genomic PCR of the GK gene

\begin{tabular}{lllll}
\hline Exon & Forward primer & Reverse primer & $\begin{array}{c}\text { Tanneal } \\
\left({ }^{2} \text { C) }\right.\end{array}$ & Product size \\
\hline 1 & PK682 cgccgtcacccaggaaaccg & PK683 acagccacccctccgtcccccg & 61 & $222 \mathrm{bp}$ \\
8,9 & PK635 acagtgttaaatacccaatcttc & PK685 tttggcttgtccaatctgg & 58 & $>4 \mathrm{~kb}$ \\
$8,9,10$ & PK635 acagtgttaaatacccaatctc* & PK686 atacacacttatggcctgta & 55 & $>9 \mathrm{~kb}$ \\
$8,9,10,11$ & PK635 acagtgttaaatacccaatcttc & PK638 gtccttcaactcaatcaaatgcc & 58 & $>9 \mathrm{~kb}$ \\
$17,18,19$ & PK647 agccctactgcagttaatgtg* & PK688 gaaccttctgaatataatgtgc & 64 & $>5 \mathrm{~kb}$ \\
19 & PK736 ttataagccacttgctgca & PK737 gttaaaagcaaagagctgctg & 55 & $350 \mathrm{bp}$ \\
\hline
\end{tabular}

ॠThese primers were described previously by Sargent et al. ${ }^{5}$

indicate either Duchenne muscular dystrophy or congenital adrenal hypoplasia.

\section{IN VIVO INVESTIGATIONS}

In order to determine the fasting tolerance, patients 1.III. 1 and 1.III.3 were subjected to a fasting test without limitation of water intake. The test was interrupted if the blood glucose value decreased below $3.0 \mathrm{mmol} / \mathrm{l}$ or if clinical hypoglycaemic symptoms developed. In addition, to determine the tolerance to fat intake, patient 1.III.1 was also subjected to a loading test with long chain triglycerides (LCT). LCT loading was done with $1.5 \mathrm{~g} \mathrm{LCT} / \mathrm{kg}$ body weight orally after an overnight fast. Blood glucose, glycerol, free fatty acids, and ketone bodies were measured up to the end of the fasting test and up to four hours after the LCT loading. Both tests were performed when the patients were aged $11 / 2$ years.

\section{MUTATION ANALYSIS}

Blood was collected from patients and their family and high molecular weight DNA was isolated from peripheral blood leucocytes using established procedures. The genomic DNA of one affected subject from each family and one unrelated normal subject was used for mutation analysis. Fifteen of the 19 exons of the GK gene (GenBank accession No X78211) were amplified using genomic primers as previously described. ${ }^{7}$ The primers for exons $1,9,10$, and 19 were designed based on the published sequences (table 2). PCR was performed on a DNA Thermal Cycler 480 (Perkin Elmer, USA) in a $100 \mu$ l reaction mixture containing $500 \mathrm{ng}$ genomic DNA, $400 \mathrm{ng}$ of each primer, $1.5 \mathrm{mmol} / \mathrm{l}$ of each $\mathrm{dNTP}, 100 \mu \mathrm{g} / \mathrm{ml}$ bovine serum albumin, and $5 \mathrm{U} / \mu \mathrm{l}$ AmpliTaq DNA polymerase (Perkin Elmer, USA), in a buffer consisting of $67 \mathrm{mmol} / \mathrm{l}$ Tris- $\mathrm{HCl}(\mathrm{pH} \mathrm{8.8)}, 6.7$ $\mathrm{mmol} / 1 \mathrm{MgCl}_{2}, 6.7 \mu \mathrm{mol} / \mathrm{l}$ EDTA, $16.6 \mathrm{mmol} / \mathrm{l}$ $\left(\mathrm{NH}_{4}\right)_{2} \mathrm{SO}_{4}, 10 \mathrm{mmol} / 1 \quad \beta$-mercaptoethanol, with or without $10 \%$ dimethylsulphoxide. After a four minute hot start at $94^{\circ} \mathrm{C}$, the amplification was performed for 40 cyles, each cycle consisting of one minute denaturation at $94^{\circ} \mathrm{C}$, one minute annealing at $55^{\circ} \mathrm{C}$ (except for exons 1,9 , and 11 ), and two minutes extension at $72^{\circ} \mathrm{C}$. Exons 1,9 , and 11 were annealed at $61^{\circ} \mathrm{C}, 53^{\circ} \mathrm{C}$, and $56^{\circ} \mathrm{C}$, respectively.

The Expand ${ }^{\mathrm{TM}}$ High Fidelity PCR system (Boehringer Mannheim, Germany) was used to amplify the long DNA fragments according to the manufacturer's instructions. The conditions used for amplification were denaturation for 45 seconds at $94^{\circ} \mathrm{C}$, annealing for 45 seconds at primers $T_{\text {anneal }}$ (table 2), and extension at $68^{\circ} \mathrm{C}$ for $4-10$ minutes (depending on fragment length). The PCRs were performed for 30 cycles, after an initial denaturation at $94^{\circ} \mathrm{C}$ for four minutes.

The amplified DNA was purified by ultra low gelling agarose, type IX, Sigma A-5030 gel electrophoresis (Sigma Chemical Company, USA). The fragments were excised and directly sequenced by the dideoxy chain termination reaction with an AmpliCycle ${ }^{\mathrm{TM}}$ sequencing kit (Perkin Elmer, USA) according to the manufacturer's instructions.

DNA sequence changes were confirmed by restriction endonuclease analysis. TaqI and NlaIII (New England BioLabs, USA) were used according to the manufacturer's instructions. The digestion products were subjected to gel electrophoresis on ethidium bromide stained agarose.

The presence of the DMD gene was confirmed using the DNA markers DXS1204, STR49, and 5'dys2. ${ }^{10}$

\section{Results}

Eight males from the three families had hyperglycerolaemia, glyceroluria, and defective ${ }^{14} \mathrm{C}$ glycerol incorporation in skin fibroblasts (table 1). Four patients from two families were essentially free of symptoms (1.I.1, 1.III.4, 3.II.1, and 3.II.2). Three patients (1.III.1, 1.III.3, and 2.II.3) had gastrointestinal symptoms with ketoacidosis or hypoglycaemia or both whereas one patient (3.II.3) had recurrent convulsions as the only acute sign without evidence that it was correlated with a catabolic state.

The fasting test in patients 1.III.1 and 1.III.3 was terminated after 19 and 20 hours, respectively (fig 2). The blood glucose value in patient 1.III. 1 was significantly reduced $(2.2 \mathrm{mmol} / \mathrm{l})$ compared with control values $(2.8-4.3 \mathrm{mmol} /$ 1), whereas the glucose in patient 1.III.3 reached $3.3 \mathrm{mmol} / 1$. At the same time, plasma glycerol had reached peak levels of 6.3 and 7.5 $\mathrm{mmol} / 1$ (control values $<0.28 \mathrm{mmol} / \mathrm{l}$ ), respectively. Together with the tendency to hypoglycaemia there was considerable hyperketonaemia and plasma 3-hydroxybutyrate values amounted to 5.8 and $6.4 \mathrm{mmol} / \mathrm{l}$ (control values $0.8-2.6 \mathrm{mmol} / \mathrm{l}$ ), respectively. Free fatty acids had increased only marginally to 0.9 and $1.8 \mathrm{mmol} / 1$ (control values $0.9-2.6 \mathrm{mmol} / \mathrm{l}$ ). It is justified to assign the term hyperketotic states to these conditions. ${ }^{11}$

The LCT loading test of patient 1.III.1 gave comparable results. The blood glucose decreased from 5.9 to $4.6 \mathrm{mmol} / \mathrm{l}$. The 3-hydroxybutyrate increased remarkably from 0.2 to $2.0 \mathrm{mmol} / \mathrm{l}$ during the four hour test, together with a concomitant increase of 


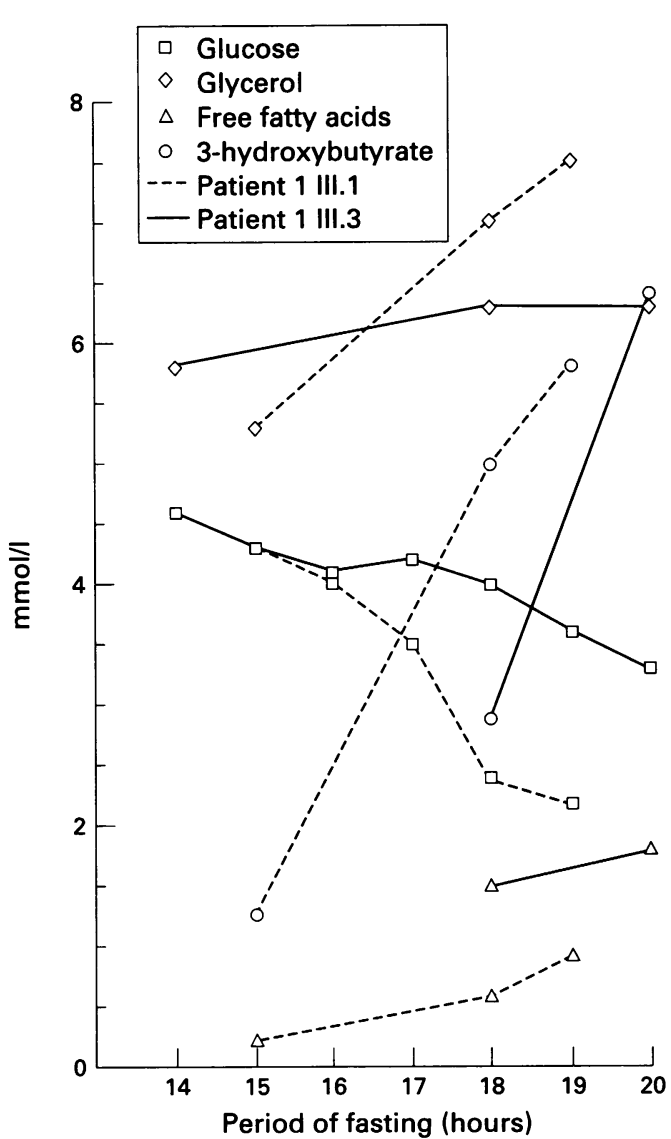

Figure 2 Profiles of plasma glucose, glycerol, free fatty acids, and 3-hydroxybutyrate during a fasting test in patients 1.III.1 and 1.III.3. Analysis of plasma at 19-20 hours'fasting showed relative hypoglycaemia accompanied by hyperketonaemia, hyperglycerolaemia, and slight increase of fatty acids. Control values are given in the Results section.

glycerol (5.0 to $6.2 \mathrm{mmol} / \mathrm{l}$ ). The urinary excretion of glycerol during this test did not change considerably (data not shown). GK gene analysis is hampered by the presence of several pseudogenes in the human genome. Therefore, a strategy had to be developed that unambiguously distinguishes the functional gene from the non-functional homologous sequences. Using the primers as reported by Sargent $e t a l$ and as given in table 2 , we were able to amplify separately exons 1 to 8 and 12 to 18 of the functional gene at the $\mathrm{Xp} 21$ locus. The flanking sequences that permit the amplification of exons 9,10 , and 11 separately have not been reported. Therefore, exons $8,9,10$, and 11 were amplified in a single fragment. Surprisingly, the sequence analysis of exon 9 of the GK gene showed an intron at the position corresponding to nt $\mathbf{8 8 0}$ of the reported DNA sequence (nt 880 gtaagtttcatcaccaagtgtctcccat ccccacccttccccatgttatggctttcctcctcttagttcatcagtg tgcctctttttaaactagggaaaacaagtaaaagttgcaaaattgg ctaattcttgttcttacatgtcatactgtgggccattgagaatctttt gaataaattaattttaactctccettccatacctattatcttacata ttaacaaatggtattaacaaatggggaaaatggccaaatggaga aaatgcaaggaaatagacagttcattctttgataaataaaaatg aaaataaatcctatggctcttctaaaaagaaagttaatactattgt attagtcagtgttctttattgtcatttatactttcag nt 881). This means that the previously reported exon 9 encompassing nucleotides 844 to 947 of the $\mathrm{GK} \mathrm{cDNA}^{7}$ actually consists of two exons. The intron itself has a length of $392 \mathrm{bp}$.
The analysis of exon 19 according to Sargent et $a l$ showed a sequence that was similar to the one designated for the chromosome 1 locus. Therefore, exons 17, 18, and 19 of the functional GK gene were amplified in a single fragment using the intronic 17 forward primer (PK647) and the exonic 19 reverse primer (PK685). Sequencing this fragment showed three nucleotides in exon 19 that differed from the published cDNA. ${ }^{7}$ Firstly, there is a transversion $G$ to $C$ at position 2224, secondly, a transition $G$ to $A$ at position 2429 , and thirdly, a $1 \mathrm{bp}$ insertion of a $\mathrm{T}$ at position 2532 . All $\mathrm{X}$ chromosomes tested were found to have these nucleotide alterations.

Subsequently, the probands of the isolated GKD families 1 (1.III.1), 2 (2.II.3), and 3 (3.II.3) were tested for GKD gene abnormalities. Analysis of the GK exons by electrophoresis on ethidium bromide stained agarose gels indicated no gross gene abnormalities in the probands of families 2 and 3. However, the proband of family 1 did not show amplification products for the fragment encompassing exons $8,9,10$, and 11 , and the downstream located exons 12-19, whereas separate amplification of exon 8 was positive. Thus, we concluded that the deletion starts downstream of exon 8. To localise the starting point of the deletion further, exons 8-9 and exons 8-10 were amplified in single fragments. The former region could be amplified, but the latter could not, indicating that the deletion in family 1 starts downstream of exon 9.

To determine the end point of the deletion in the proband of family 1 (1.III.3), we selected a primer pair (PK736/PK737) to amplify specifically exon 19 of the functional GK gene. However, the analysis of this fragment in controls still indicated two sequences. At position 2134, both a $\mathrm{T}$ of the active gene and an $\mathrm{A}$ of the pseudogene (Xq clone 817 ) were present. ${ }^{7}$ We analysed this part of the gene for the proband and his family members. The mother of the proband (1.II.2), his unaffected brother (1.III.2), and the normal control show both a $T$ and an $A$ at position 2134, whereas the proband shows only the $A$. The control sequence of exon 19 from an exon 17-19 PCR fragment, which is specific for the active gene, shows only the $T$. The absence of the $T$ in the proband indicates that the active GK gene has been deleted (data not shown). Further examinations of the DNA using markers DXS1214, STR49, and 5 'dys $2^{10}$ indicated the presence of the DMD gene.

The probands of families 2 and 3 did not show any gross gene abnormalities. Therefore, the amplified GK exons were sequenced. Exon 15 in patient 2.II.3 showed a C1351T transition (fig 3A). This single base change is a nonsense mutation and is designated R413X. The mutation abolishes a TaqI restriction site, resulting in $696 \mathrm{bp}$ and 222 bp fragments, instead of the $517 \mathrm{bp}, 222 \mathrm{bp}$, and $179 \mathrm{bp}$ fragments (fig 3B). This provides a rapid screening method. TaqI restriction enzyme analysis of this family confirmed that the patient is 

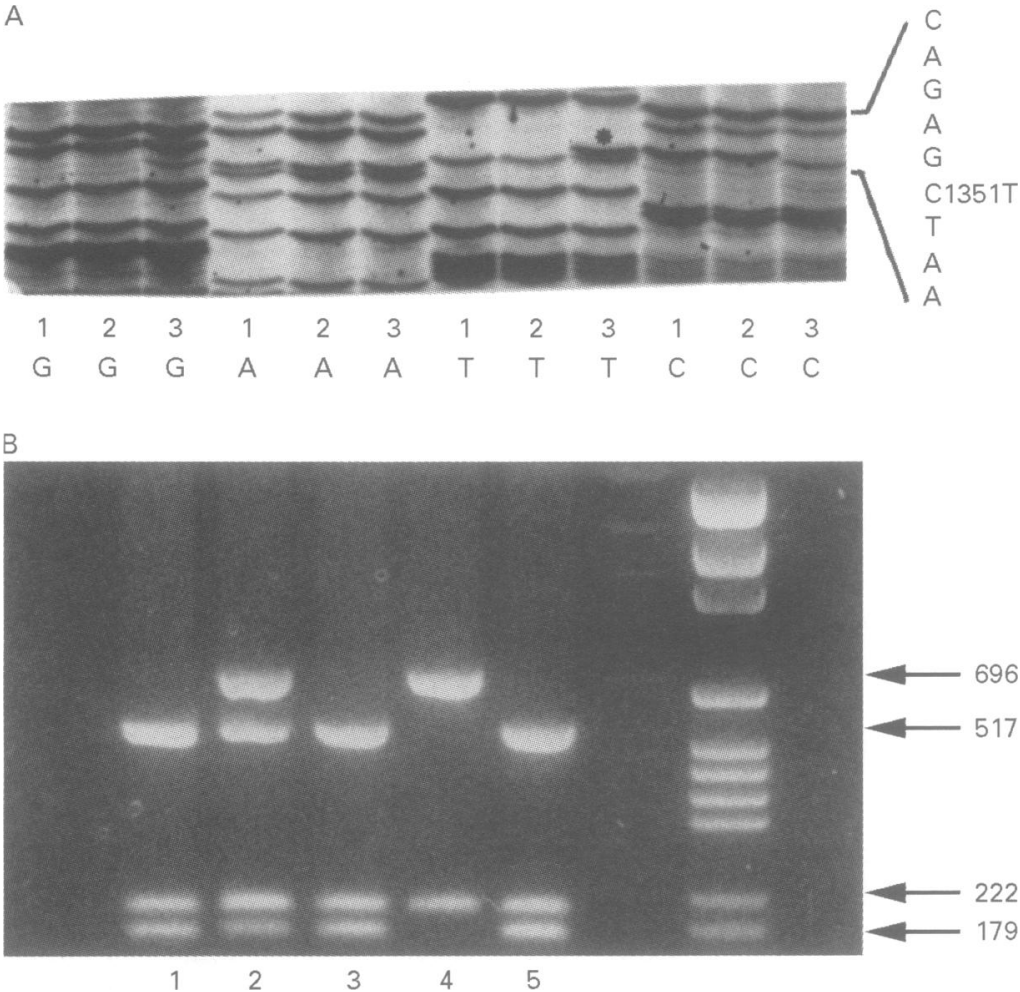

Figure 3 (A) Mutation analysis of exon 15 of the $G K$ gene in family 2. The sequence of exon 15 is given on the right side of the figure; an asterisk indicates the position of the C1351T mutation in patient 2.II.3. Lane 1-2, normal subjects, lane 3, patient 2.II.3. (B) The C1351T mutation abolishes a TaqI restriction site, resulting in $222 b p$ and $696 b p$ fragments, instead of the $517 \mathrm{bp}, 222 \mathrm{bp}$, and $179 \mathrm{bp}$ fragments. TaqI restriction analysis of members of family 2 are shown. Lane 1, father (2.I.1), lane 2, mother (2.1.2), lane 3, sister (2.II.2), lane 4, patient (2.II.3), and lane 5, unrelated normal female.

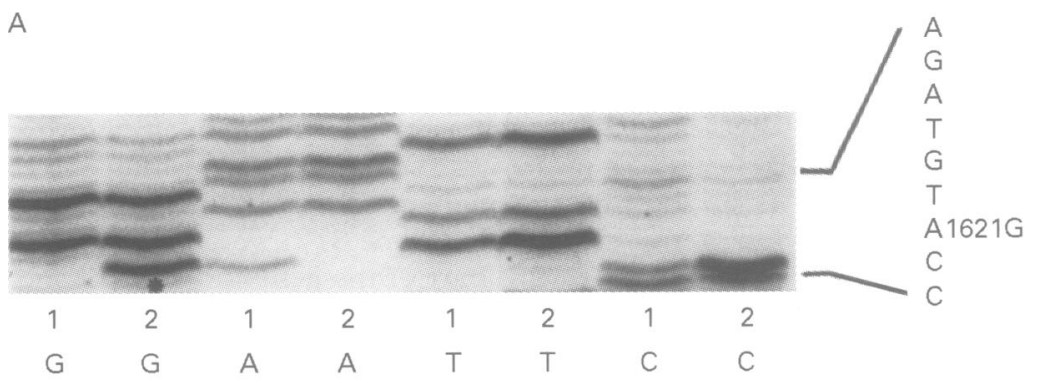

B

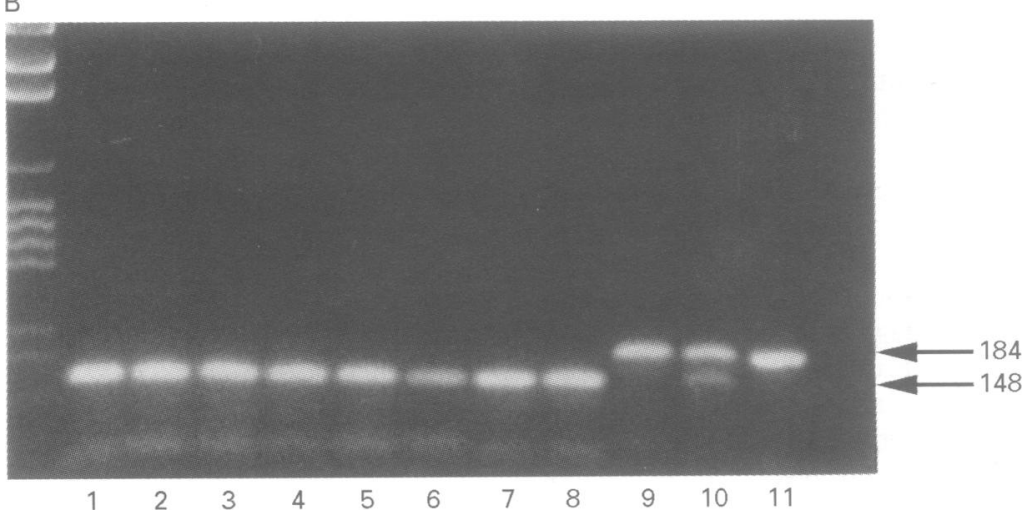

Figure 4 (A) Mutation analysis of the non-coding strand of exon 17 of the GK gene in family 3. The sequence of exon 17 is given on the right side of the figure; an asterisk indicates the transition at position $1621(A \rightarrow G$ (non-coding strand) $\approx T \rightarrow C$ (coding strand)) in patient 3.II.3. Lane 1, normal subjects, lane 2, patient 3.II.3. (B) The T1621C mutation abolishes an NlaIII restriction site, resulting in a $184 \mathrm{bp}$ fragment instead of the $148 \mathrm{bp}$ and $36 \mathrm{bp}$ fragments. NlaIII restriction analysis of members of family 3 and eight unrelated normal females are shown. Lanes 1-8, unrelated normal females, lane 9, patient 3.II.1, lane 10, mother (3.I.2), lane 11, patient 3.II.3. An additional 42 normal females samples were also tested (not shown). hemizygous for the R413X mutation, while his mother is heterozygous (lanes 4 and 2, respectively).

In patient 3.II.3, a T1651C transition has occurred in codon 503, resulting in a W503R amino acid substitution (fig 4A). This transition abolished an NlaIII restriction enzyme site, resulting in a $184 \mathrm{bp}$ fragment instead of $148 \mathrm{bp}$ and $36 \mathrm{bp}$ fragments (fig 4B). NlaIII restriction enzyme analysis of this family showed that the patient and his two brothers (3.II.1 and 3.II.2) are hemizygous for the W503R mutation, while his mother (3.I.2) is heterozygous (lanes 9,11 , and 10 respectively). No further nucleotide differences were found The W503R mutation was not present in 50 normal unrelated females.

\section{Discussion}

The GK gene structure showed several discrepancies in comparison to the previously published sequences. Firstly, the cDNA sequence encompassing nucleotides 844 to 947 , which has been designated exon $99^{7}$ actually contains an intron between $\mathrm{nt} 880$ and nt 881 . The intron has a length of $392 \mathrm{bp}$, starts with a gtaagt sequence, and ends with a gtcatttatactttcag sequence. These sequences fit the consensus sequences for the 5' (donor) and 3' (acceptor) splice sites, respectively. ${ }^{12}{ }^{13}$ Consequently, this new finding changes the number of GK gene exons from 19 to 20 exons, and accordingly the numbering of the downstream exons should be adjusted (fig 5) (here, we still use the published numbers). Secondly, the sequence of exon 19 of the GK gene differs from published cDNA libraries ${ }^{7}$ at three positions, all located in the 3 ' untranslated coding region. We have proven that these discrepancies were in the active gene and not in the pseudogenes or in the processed, expressed genes. This sequence was detected in all $\mathrm{X}$ chromosomes tested and therefore probably these nucleotide differences represent polymorphisms.

DNA analysis of the entire GK gene coding region of the probands of the three isolated GKD families showed three novel mutations: a large deletion, a nonsense mutation, and a missense mutation. An deletion of at least $20 \mathrm{~kb}$ in the GK gene was identified in the patients of family 1 and extended from downstream of exon 9 to at least the $3^{\prime}$ end of the gene. The nonsense mutation (R413X) in exon 15 of family 2 is predicted to reduce the amount of mutant allele transcript. ${ }^{14}$ The association between nonsense mutations that create stop codons before the penultimate exon and reduced cytoplasmic levels of mutant mRNA is well documented. ${ }^{15}$ In family 3 , a T1621C was found in exon 17, which leads to the replacement of tryptophan by arginine at position 503 . The W503R mutation was considered as the causative gene defect because: (1) no other gene abnormalities were identified, (2) it would substitute the hydrophobic tryptophan for the positively charged arginine, (3) tryptophan 503 may be essential for the functioning of the GK protein since it is conserved in rat, mouse, $E$ 


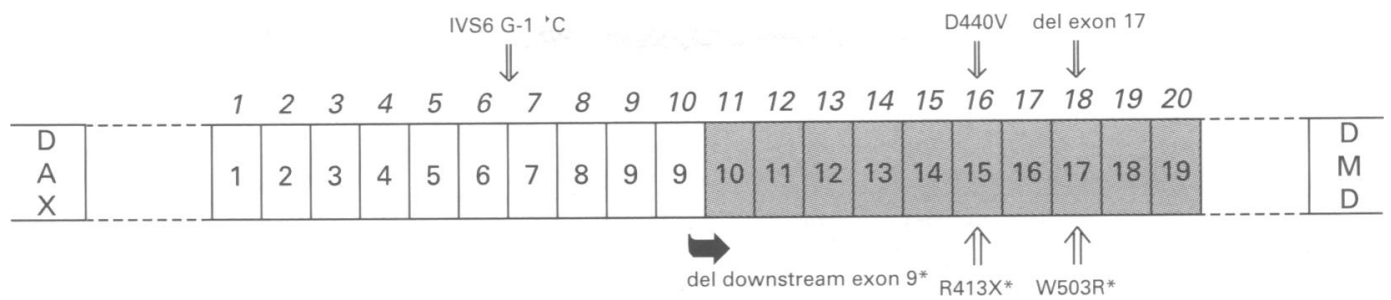

Figure 5 Schematic representation of the GK gene. The positions of the different mutations are indicated by arrows. The asterisk indicates the mutations found in this study. The remaining mutations were described by Walker et al. ${ }^{9}$ The boxes indicate the exons. The numbers inside the boxes indicate the published exon numbering. The numbers outside the boxes indicate the new exon numbering according to the new gene structure (the novel intronic sequence between $n t 880$ and $n t$ 881 , which has separated the previously reported exon 9 into two exons).

coli, and $B$ subtilis, ${ }^{816}$ and (4) it was absent in 100 alleles from 50 unrelated normal females.

Although the affected members of families 1 and 3 showed the same genetic and biochemical defect within the family, the phenotypic variability of the disease was remarkable. The proband of family 1 (1.III.1) has shown symptoms of vomiting, acidaemia, and progressive lethargy, consistent with the phenotypic presentation observed in previous patients with symptomatic GKD. ${ }^{1}$ One of his cousins (1.III.3) only presented with hypoglycaemia in the first few hours of life, perhaps related to his dysmaturity. ${ }^{17}$ In contrast, his other cousin (1.III.4) and his maternal grandfather (1.I.1) have always been in good health. In family 3, the proband (3.II.3) experienced generalised seizures, without evidence that this was associated with a catabolic state, and severe psychomotor retardation, whereas his two older brothers were asymptomatic up to their present ages of $81 / 2$ and 4 years. Blomquist et al ${ }^{18}$ have also reported two brothers with and without clinical manifestations. The clinical variability within a family may be caused by the fact that patients with a benign clinical course have not been challenged metabolically. ${ }^{1}$

Poor oral intake, intercurrent illness, or exercise are the potential challenging conditions. Under these conditions, the exogenous caloric intake is generally insufficient to meet the energy demand, so that the first priority of metabolism is to provide sufficient glucose to the brain and other tissues that are absolutely dependent on this fuel. Since hepatic glycogen is depleted within several hours of fasting, hepatic glucose output becomes dependent on gluconeogenesis during prolonged fasting. Glycerol is a gluconeogenic substrate that under non-fasting conditions contributes only to a small percentage of the total hepatic glucose output, but during fasting it contributes about one-fifth of the total hepatic glucose output, at least in adults. ${ }^{19}$ Whether this $20 \%$ reduction of the gluconeogenic capacity in GKD is sufficient to cause hypoglycaemia remains to be investigated. In fact, patients 1.III.1 and 1.III.3, who were investigated with fasting tests, suffered from hyperketosis with and without hypoglycaemia, respectively. Lethargy that was shown by patients 1.III.1 and 2.II. 3 and seizures by patient 3. II. 3 could be classified as neuroglycopenic symptoms, which developed from the direct effect of glucose deprivation on higher mental function. ${ }^{20}$ The pathogenesis of psychomotor retardation in GKD is not known, but might be the result of subclinical episodes of hypoglycaemia. Disturbance of energy homeostasis was recently shown in glycerol kinase deficient mice. ${ }^{21}$ This observation adds to the evidence that $\mathrm{GK}$ has an important role in the regulation of energy generation.

Hyperglycerolaemia may also have some effect on the gluconeogenesis from other substrates because (1) in vivo tolerance tests in rats have shown that glycerol was a weak inhibitor of two key enzymes of gluconeogenesis, fructose-1,6-diphosphatase and phosphoenolpyruvate carboxykinase, ${ }^{22}$ and (2) glycerol may reduce glucose formation from alanine, one of the major gluconeogenic substrates. ${ }^{23}$ This may be an additional factor in the regulation of gluconeogenesis in $\mathrm{GKD}$, which has not been investigated so far.

The hyperketonaemia in patients 1.III.1 and 1.III. 3 could be the consequence of decreased gluconeogenesis; however, the possibility of underuse of ketone bodies should not be overlooked..$^{10}$ Both the in vivo rate of ketone body production/removal and the true rate of gluconeogenesis from various substrates other than glucose should be investigated in these patients. An approach using stable isotopes is currently being developed in an attempt to gain additional insights into the pathophysiology of the disease. The loading test with LCT showed a quite impressive increase of plasma ketone body concentrations. This again may be because the test was done after an overnight fast, at which time gluconeogenesis was possibly compromised.

In conclusion, our data suggest that the clinical variability in these GKD families cannot be explained by molecular heterogeneity. Environmental factors predisposing to metabolic decompensation may largely contribute to the phenotypic variability.

We would like to acknowledge the technical advice of Mrs I A J de Valk and Mr R A Zewald. DRS, paediatrician, is a staf member of the Department of Child Health, Dr Cipto Mangunkusumo National General Hospital, University of Indonesia School of Medicine, Jakarta. She is recipient of a grant from the Van Deventer-Maas Foundation, The Netherlands. We also thank Dr E Bakker, Sylvius Laboratory University of Leiden, The Netherlands for additional molecular studies.

1 McCabe ER. Disorders of glycerol metabolism. In: Scriver CR, Beaudet AL, Sly WS, Valle D, eds. The metabolic and molecular bases of inherited disease. 7th ed. New York McGraw Hill, 1995:1631-43.

2 Scheuerle A, Greenberg F, McCabe ER. Dysmorphic features in patients with complex glycerol kinase deficiency. P Pediatr 1995;126:764-7.

3 Wise JE, Matalon R, Morgan AM, McCabe ER. Phenotypic features of patients with congenital adrenal hypoplasia and glycerol kinase deficiency. Am $\mathcal{F}$ Dis Child 1987;141:744-7. 
4 McCabe ERB, Sadava D, Bullen WW, McKelvey HA, Seltzer WK, Rose CI. Human glycerol kinase deficiency: enzyme kinetics and fibroblast hybridization. F Inherit Metab Dis 1982;15:177-82.

5 Walker AP, Muscatelli F, Monaco AP. Isolation of human $\mathrm{Xp} 21$ glycerol kinase gene by positional cloning. Hum Mol Genet 1993;2:107-14.

6 Guo W, Worley K, Adams V, et al. Genomic scanning for expressed sequences in $\mathrm{Xp} 21$ identifies the glycerol kinase gene. Nat Genet 1993;4:367-72.

7 Sargent CA, Young C, Marsh S, Ferguson-Smith MA, Affara NA. The glycerol kinase gene family: structure of the $\mathrm{Xp}$ gene, and related intronless retroposons. Hum Mol Genet 1994;3:1317-24.

8 Huq AHMM, Lovell RS, Sampson MJ, et al. Isolation, mapping, and functional expression of the mouse $\mathrm{X}$ chromoping, and functional expression of the mouse X ch

9 Walker AP, Muscatelli F, Stafford AN, et al. Mutations and phenotype in isolated glycerol kinase deficiency. Am $\mathcal{F ~ H u m}$ Genet 1996;58:1205-11.

10 Willard HF, Cremers F, Mandel JL, Monaco AP, Nelson $\mathrm{DL}$, Schlessinger D. Report of the fifth international workshop on human X chromosome mapping 1994. Cytogene Cell Genet 1994;67:296-328.

11 Bonnefont JP, Specola NB, Vassault A, et al. The fasting test in paediatrics: application to the diagnosis of pathological hypo- and hyperketotic states. Eur F Pediatr 1990;150:80-5.

12 Senapathy $P$ Shapiro MB, Harris NL Splice junctions, branch point sites, and exons: sequence statistics, identification, and applications to genome project. Methods Enzymol 1990;183:254-78.

13 Krawczak M, Reiss J, Cooper DN. The mutational spectrum of single base-pair substitutions in mRNA splice junctions of human genes: causes and consequences. Hum jenet 1992;90:41-54.
14 McIntosh I, Hamosh A, Dietz HC. Nonsense mutations and diminished mRNA levels. Nat Genet 1994;4:219.

15 Dietz HC, McIntosh I, Sakai LY, et al. Four novel FBN1 mutations: significance for mutant transcript level and EGF-like domain calcium binding in the pathogenesis of Marfan syndrome. Genomics 1993;17:468-75.

16 Guo W, Worley K, Adams V, et al. Genomic scanning for expressed sequences in Xp21 identifies the glycerol kinase gene. Nat Genet 1993;4:367-72.

17 Patel D, Kalhan S. Glycerol metabolism and triglyceridefatty acid cycling in the human newborn: effect of maternal diabetes and intrauterine growth retardation. Pediatr Res 1992;31:52-8.

18 Blomquist HK, Dahl N, Gustafsson L, et al. Glycerol kinase deficiency in two brothers with and without clinical manifestations. Clin Genet 1996;50:375-9.

19 Baba H, Zhang XJ, Wolfe RR. Glycerol gluconeogenesis in fasting humans. Nutrition 1995;11:149-53.

20 Deary IJ, Hepburn DA, MacLeod KM, Frier BM. Partitioning the symptoms of hypoglycaemia using multisample confirmatory factor analysis. Diabetologia 1993;36: 771-7.

21 Huq AHMM, Lovell RS, Ou CN, Beaudet AL, Craigen WJ. $\mathrm{X}$-linked glycerol kinase deficiency in the mouse leads to growth retardation, altered fat metabolism, autonomous glucocorticoid secretion and neonatal death. Hum Mol Genet 1997;6:1803-9.

22 Wapnir RA, Stiel L. Regulation of gluconeogenesis by glycerol and its phospohorylated derivatives. Biochem Med 1985;33:141-8.

23 Jahoor F, Peters EJ, Wolfe RR. The relationship between gluconeogenic substrate supply and glucose production in humans. Am F Physiol 1990;258:E288-96. 